Abstract-The time series of estimated fishery exploitation rates for endangered Sacramento River winter Chinook salmon (Oncorhynchus tshawytscha) is confined to a relatively recent period for which coded-wire tag data have been available. However, the nature of ocean salmon fisheries before this period was substantially different, and it is likely that recent exploitation rates do not represent the level of fishing mortality experienced by these Chinook salmon in earlier years. To infer historical exploitation rates, a model was developed to hindcast the impact rate for age-3 winter Chinook salmon (an approximation of the exploitation rate) by using 35 years of fishing effort estimates coupled with contemporary estimates of fishery encounter rates. The impact-rate hindcasts were highest during a period from the mid-1980s through the mid-1990s. Over time, the proportion of the impact rate attributed to commercial and recreational fisheries diverged from approximately equal shares early in the time series to an impact rate mostly composed of recreational fishery-induced mortality in more recent years. The inferred exploitation rates provide context for the fishing-induced mortality experienced by winter Chinook salmon both before and after the time of the initial inclusion of this species on the Endangered Species Act (ESA) list in 1989 and through a dynamic period for ocean salmon fisheries in California.

Manuscript submitted 1 October 2014. Manuscript accepted 2 June 2015. Fish. Bull. 113:341-351 (2015). Online publication date: 16 June 2015. doi: 10.7755/FB.113.3.9

The views and opinions expressed or implied in this article are those of the author (or authors) and do not necessarily reflect the position of the National Marine Fisheries Service, NOAA.

\title{
Inferred historical fishing mortality rates for an endangered population of Chinook salmon (Oncorhynchus tshawytscha)
}

\author{
Michael R. O'Farrell (contact author) \\ William H. Satterthwaite \\ Email address for contact author: michael.ofarrell@noaa.gov \\ Fisheries Ecology Division \\ Southwest Fisheries Science Center \\ National Marine Fisheries Service, NOAA \\ 110 Shaffer Road \\ Santa Cruz, California 95060
}

Determining the status of a stock often entails estimation of the population state or exploitation rate in relation to a baseline period before, or in the early stages of, a developing fishery. For example, determinations of an overfished status for many fish populations rely on estimates of depletion: the spawning stock biomass expressed as a fraction of its unfished level (Restrepo and Powers, 1999; Haltuch et al., 2008). The determination of Endangered Species Act (ESA) status for Pacific salmon (Oncorhynchus spp.) populations include analysis of current abundance levels in relation to the habitat carrying capacity and historical population abundance (Myers et al., 1998). The effect of fisheries (e.g., overfishing) generally is inferred from a time series of exploitation rate estimates that are compared with benchmarks of sustainable or optimal fishing-induced mortality rates. Estimation of historical fishing mortality rates is a focus of stock assessment, and such estimates are necessary inputs into life cycle models that allow inferences to be drawn regarding population dynamics in the face of competing sources of mortality (Hendrix et al., 2014). Because there are often only short data series available for many stocks of conservation concern to allow evaluation of their status, development of approaches that can extend estimated abundance or exploitation rates retrospectively can improve our historical understanding of a stock's dynamics.

For Pacific salmon, the time series of estimated exploitation rates can often be quite short because stockspecific catch data must be garnered from mixed-stock ocean fisheries, where the stock of origin cannot be determined visually, and therefore the estimate of exploitation rates requires tagging data (most commonly with a coded-wire tag; Johnson, 1990; Lapi et al., 1990; Nandor et al., 2010) or potentially genetic data (Milner et al., 1985; PSC1; Satterthwaite et al., 2014). Estimates of exploitation rates are frequently confined to a period of time after major changes in the fishing capacity of fleets, allowing for only a glimpse of

${ }^{1}$ PSC (Pacific Salmon Commission). 2008. Recommendations for application of genetic stock identification (GSI) methods to management of ocean salmon fisheries. Special report of the GSI steering committee and the Pacific Salmon Commission's committee on scientific cooperation. Pacific Salmon Comm. Tech. Rep. 23, 35 p. [Available at website.] 


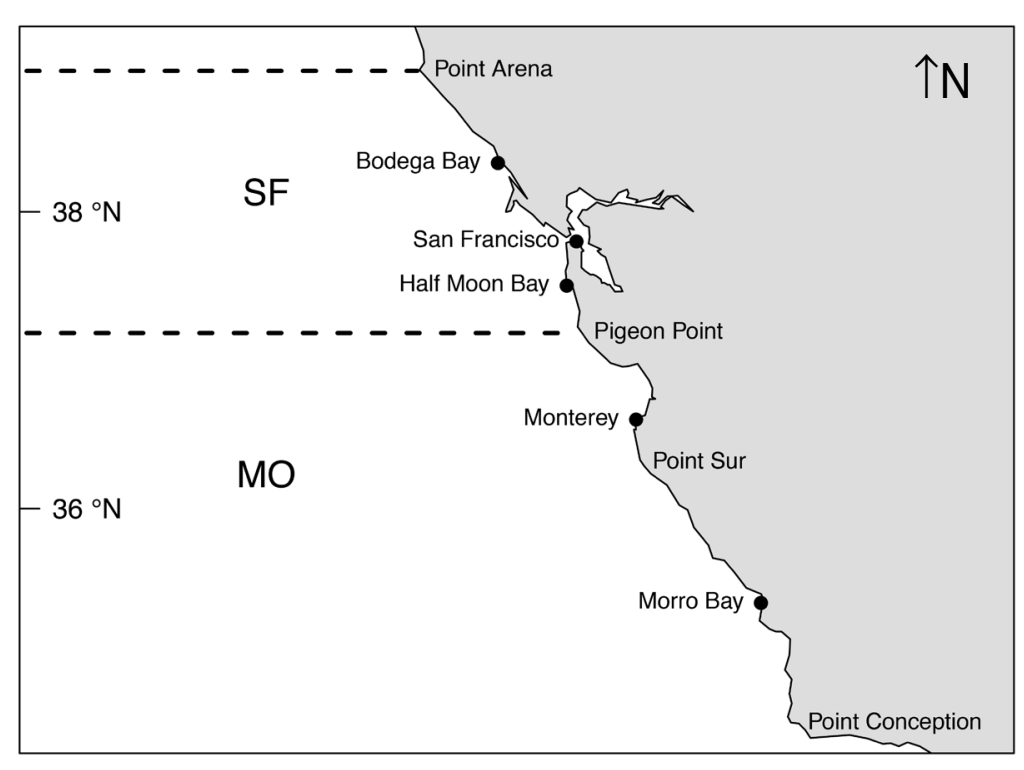

Figure 1

Map of the central California coastline, with the northern boundaries of the San Francisco (SF) and Monterey (MO) management areas denoted by dashed lines.

how exploitation has varied historically. This general condition applies to both target stocks in fisheries, as well as ESA-listed stocks that are taken in fisheries as incidental catch.

Sacramento River winter Chinook salmon (Oncorhynchus tshawytscha) (SRWC), named for the season of freshwater spawning return, were first listed under the ESA in 1989 as threatened and then as endangered in 1994 (Federal Register, 1994). The Sacramento River winter Chinook Evolutionarily Significant Unit, currently composed of a single population that spawns in the Sacramento River downstream from Keswick and Shasta dams near Redding, California, has experienced a heavy decline in abundance (Fisher, 1994; Yoshiyama et al., 1998). Fisher (1994) reported a potential maximum spawning run size of 200,000 before dam construction and a spawning stock estimate of more than 100,000 fish in the late 1960s (after dam construction). Estimates published by the Pacific Fishery Management Council (PFMC) $\left(\mathrm{PFMC}^{2}\right)$ indicate a run size of more than 30,000 fish in the early 1970 s and run sizes below 1000 fish for several years since 1980 .

The time series of exploitation rates estimated for SRWC is much shorter than the time series for escapement. O'Farrell et al. (2012a) used cohort reconstruction methods (Hilborn and Walters, 1992) to estimate broad year exploitation rates, referred to as the spawn-

\footnotetext{
2 PFMC (Pacific Fishery Management Council). 2014. Review of 2013 ocean salmon fisheries: stock assessment and fishery evaluation document for the Pacific coast salmon fishery management plan, $371 \mathrm{p}$. (Document prepared for the Council and its advisory entities.) Pacific Fishery Management Council, Portland, OR [Available at website.]
}

er reduction rate and defined as the reduction in a brood's potential adult spawner escapement that is caused by ocean fisheries in relation to escapement potential in the absence of ocean fishing. A cohort-reconstruction model was applied to data generated from the SRWC marking (with adipose fin clips) and tagging (with coded-wire tags) program initiated at Livingston Stone National Fish Hatchery in 1998. Before 1998, hatchery supplementation of SRWC was sporadic and the marking and tagging data were insufficient for estimation of exploitation rates. The impact rate for age-3 SRWC (hereafter referred to as the impact rate) is a measure of the fishing mortality rate on age-3 fish that corresponds closely to the exploitation rate for SRWC. The correspondence between the brood-year exploitation rate and the impact rate is due to the very high maturation rates of age-3 SRWC that result in few age- 4 fish remaining in the ocean to contribute to catch or spawner escapement (O'Farrell et al., 2012a). The impact rate is estimated annually and published in PFMC reports (e.g., $\mathrm{PFMC}^{3}$ ).

Although the estimated impact rates quantify the recent (during and after the year 2000) salmon fishing-induced mortality (hereafter "fishery mortality") on SRWC, this period follows the implementation of conservation measures designed to reduce impacts on SRWC and changes in ocean fisheries owing to management measures intended for other stocks. Salmon fisheries south of Point Arena, California (Fig. 1), are responsible for the vast majority of SRWC harvest (O'Farrell et al., 2012a; Satterthwaite et al., 2013), and many of the constraints on fisheries in this region have been intended to protect SRWC. For example, recreational fisheries in this region routinely began in midFebruary, but since the early 1990s the starting date gradually moved later in the year. Since 2004, no fisheries have occurred in February or March. Increased minimum size limits (e.g., $>20$ in [51 cm] in total length) have been imposed on the recreational sector in an effort to reduce retention of SRWC. For a variety of reasons associated with increased constraints on ocean fishing that have resulted from ESA listings and river (versus-ocean) allocations of harvest, the commercial sector has seen a reduction in participation of vessels with California salmon permits since the early 1980s $\left(\mathrm{PFMC}^{2}\right)$. The time series of commercial and recreational fishing effort south of Point Arena (Fig. 2) indicates that substantial changes in ocean fishery ef-

\footnotetext{
${ }^{3}$ PFMC (Pacific Fishery Management Council). 2015. Preseason report I: stock abundance analysis and environmental assessment part 1 for 2015 ocean salmon fishery regulations, 135 p. (Document prepared for the Council and its advisory entities.) Pacific Fishery Management Council, Portland, OR. [Available at website.]
} 
fort have occurred since the late 1970s and the inferred fishing effects for recent SRWC cohorts may not be indicative of earlier exploitation patterns.

In this article, we describe a model for the hindcasting of fishery impact rates to assess the implications for SRWC fishing mortality resulting from changes in California salmon fisheries that have occurred over the past 35 years. The model uses data on historical fishery regulations and estimates of fishing effort in California salmon fisheries in 1978-2012, and it couples these estimates with contact (i.e., fishery encounter) rates per unit of fishing effort estimated for recent years (20002012), to generate hindcasts of the impact rate for years when direct estimation is not possible. To fully parameterize the model, we developed a procedure to infer contact rates per unit of effort for months when no direct estimates exist because of the contraction of modern fisheries in relation to fisheries from the 1970s through the 1990s. The model structure is similar to the Winter Run Harvest Model (WRHM; O'Farrell et al., 2012b), a tool used to forecast the impact rate during the annual PFMC salmon fishery planning process. Although we are not able to reconstruct the complete SRWC exploitation history, the extension of the impact rate time series back to 1978 encompasses a dynamic period for California ocean salmon fisheries and provides more context for the current levels of ocean fishing mortality.

\section{Materials and methods}

\section{Impact-rate model}

The data and model used for this analysis were stratified by year $(y)$, month $(t)$, management area $(z)$, and fishery sector $(x)$. Because harvest of SRWC is rare north of Point Arena, California (O'Farrell et al., 2012a; Satterthwaite et al. 2013), the spatial extent of our model is limited to the 2 ocean management areas south of Point Arena: San Francisco (SF) and Monterey (MO) (Fig. 1). The MO management area extends from Pigeon Point to the border of the United States and Mexico, but salmon harvest is generally small and more variable south of Point Sur. Fishery sectors include commercial and recreational.

Fishery impacts $(I)$ included fish that died because they were retained as harvest $(H)$, fish that were released because they were smaller than the minimum size limit and died because of release mortality $(S)$, and fish that died from "dropoff" mortality $(D)$ that occurs when fish are encountered by fishing gear but not successfully retrieved. Mortality related to an encounter with gear can come from multiple sources, such as a

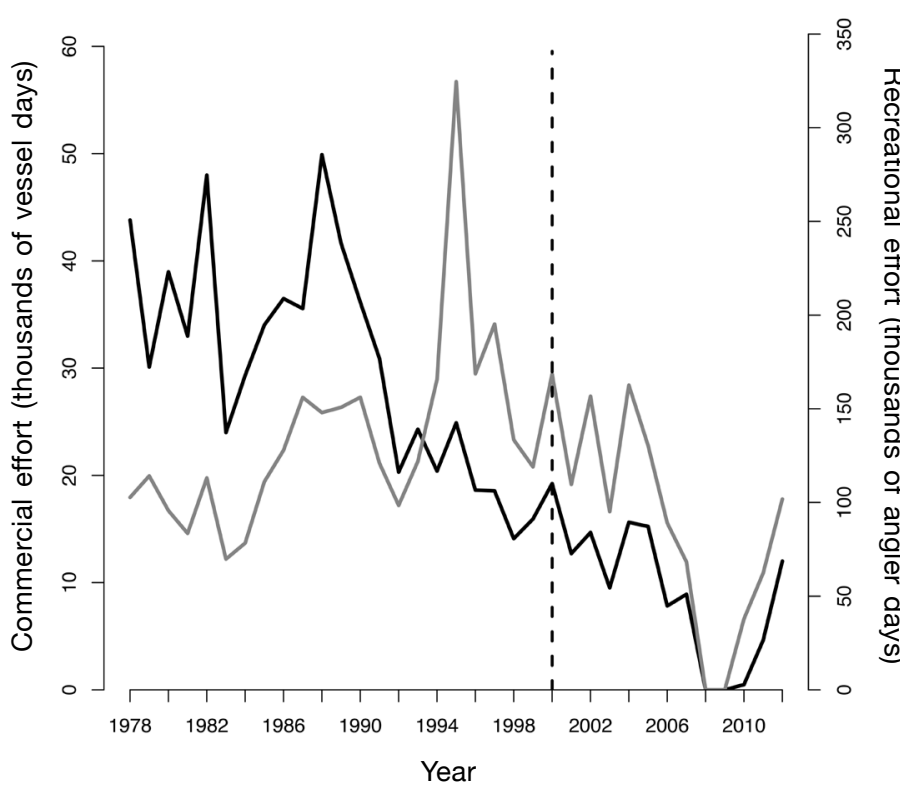

Figure 2

Estimates of commercial (black line) and recreational (gray line) sector fishing effort for the years 1978-2012 in ocean areas south of Point Arena, California. Direct estimates of the Sacramento River winter Chinook salmon (Oncorhynchus tshawytscha) impact rate have been made with cohort reconstruction methods for the years to the right of the dashed line (post-2000). Note that fishing effort units differ between the commercial and recreational fisheries and are not directly comparable.

hooking injury or predators $\left(\mathrm{PFMC}^{4}\right.$, and the references therein). The impact rate is defined as the total fishing mortality, acute and delayed, divided by the starting cohort abundance.

The impact-rate model simulates the age-3 cohort abundance from the beginning of age $3, t=$ February of year $(y)$, to $t=$ January of year $y+1$,

$$
N_{\mathrm{t}+1}=\left(N_{\mathrm{t}}-I_{\mathrm{t}}\right)(1-v) \text {. }
$$

by deducting monthly impacts, $I_{\mathrm{t}}=\sum_{\mathrm{z}, \mathrm{x}} I_{\mathrm{t}, \mathrm{z}, \mathrm{x}}$, and accounting for the natural mortality rate $v$. Application of Equation 1 over months $t$ enables the computation of the annual impact rate, defined as the sum of monthly impacts divided by the initial abundance of age- 3 fish:

$$
i=\frac{\Sigma_{\mathrm{t}} I_{\mathrm{t}}}{N_{\mathrm{t}=\text { February }}} \text {. }
$$

Impacts are computed from a string of equations initiated by an estimate of the contact rate $c$, which is formulated as the contact rate per unit of effort $\beta$, multiplied by the amount of fishing effort $f$,

\footnotetext{
${ }^{4}$ PFMC (Pacific Fishery Management Council). 2000. STT recommendations for hooking mortality rates in 2000 recreational ocean Chinook and coho fisheries. STT Rep. B.2, 18 p. Pacific Fishery Management Council, Portland, OR. [Available at website.]
} 


$$
c_{\mathrm{t}, \mathrm{z}, \mathrm{x}}=\beta_{\mathrm{t}, \mathrm{z}, \mathrm{x}} \times f_{\mathrm{t}, \mathrm{z}, \mathrm{x}} .
$$

The number of fish contacted $(C)$ is computed by multiplying the oceanwide abundance of the SRWC age-3 cohort by the contact rate:

$$
C_{\mathrm{t}, \mathrm{z}, \mathrm{x}}=c_{\mathrm{t}, \mathrm{z}, \mathrm{x}} \times N_{\mathrm{t}},
$$

where contacts represent the number of fish that encountered the fishing gear and were retrieved to the boat. Impacts are the sum of harvest, release, and dropoff mortality:

$$
I_{\mathrm{t}, \mathrm{z}, \mathrm{x}}=H_{\mathrm{t}, \mathrm{z}, \mathrm{x}}+S_{\mathrm{t}, \mathrm{z}, \mathrm{x}}+D_{\mathrm{t}, \mathrm{z}, \mathrm{x}}
$$

where

$$
\begin{gathered}
H_{\mathrm{t}, \mathrm{z}, \mathrm{x}}=C_{\mathrm{t}, \mathrm{z}, \mathrm{x}} \times p_{\mathrm{t}, \mathrm{z}, \mathrm{x}}, \\
S_{\mathrm{t}, \mathrm{z}, \mathrm{x}}=\left(C_{\mathrm{t}, \mathrm{z}, \mathrm{x}}-H_{\mathrm{t}, \mathrm{z}, \mathrm{x}}\right) \times s_{\mathrm{t}, \mathrm{z}, \mathrm{x}},
\end{gathered}
$$

and

$$
D_{\mathrm{t}, \mathrm{z}, \mathrm{x}}=C_{\mathrm{t}, \mathrm{z}, \mathrm{x}} \times d .
$$

In these equations, release and dropoff mortality rates are denoted by $s$ and $d$, respectively, and $p$ is the estimated proportion of the cohort that is greater than or equal to the legal size for retention in the fishery.

\section{Data, parameters, and variables}

Effort in California ocean salmon fisheries was estimated by the California Department of Fish and Wildlife (CDFW) on the basis of landing receipts from the commercial sector and dockside samples from the recreational sector. Units of fishing effort are the number of vessel days (the number of days fished by commercial salmon vessels) for the commercial sector and number of angler days for the recreational sector. Fishing effort for the years 1978-2012 are reported in $\mathrm{PFMC}^{2}$ and an electronic record of the historical ocean salmon fishery effort and landings for the U.S. West Coast $\left(\mathrm{PFMC}^{5}\right)$, maintained by the PFMC. Records of minimum size limits in California ocean fisheries for the years 1978-2012 were obtained from PFMC $^{2}$ and an electronic record of the historical ocean salmon fishery regulations for the U.S. West Coast $\left(\mathrm{PFMC}^{6}\right)$, maintained by the PFMC.

Coded-wire tag recovery data from ocean and river sampling programs were used in cohort reconstructions for SRWC to estimate contact and impact rates in ocean fisheries for the years 2000-2012, following the methods described in O'Farrell et al. (2012a). Cohort reconstruction is the sequential estimation of a cohort's abundance from the end of that cohort's life span, when abundance is zero, to a specified earlier age (commonly age 2). Age-specific spawner escapement and harvest

\footnotetext{
5 PFMC (Pacific Fishery Management Council). 2014. Ocean salmon fishery effort and landings (Review Appendix A). Excel workbook. PFMC, Portland, OR. [Available at website.] ${ }^{6}$ PFMC (Pacific Fishery Management Council). 2014. Ocean salmon fishery regulations and chronology of events (Review Appendix C). PFMC, Portland, OR. [Available at website.]
}

data are required, and natural mortality rates are assumed. Fishery contacts stratified by age, month, management area, and fishing sector were computed by expanding the harvest by the estimated proportion of SRWC expected to be larger than or equal to the minimum size limit $(C=H / p)$. Given an estimate of $C$, and the estimated abundance $N$, the contact rate was estimated by rearranging Equation 4 as follows: $c=C / N$. The impact rate was estimated from cohort reconstruction in the same manner as that shown in Equation 2.

It was implicitly assumed that contact and impact rates estimated from tagged, hatchery-origin fish are representative of the natural-origin SRWC population. Although it is difficult to directly evaluate this common assumption $\left(\mathrm{PSC}^{7}\right)$, there is some evidence that hatchery-origin indicator stocks have similar ocean distributions and fishery exposure as those estimated for untagged stocks for which they serve as proxies (Weitkamp and Neely, 2002; Satterthwaite et al., 2014). The hatchery-origin component of the total SRWC abundance is only a portion of the total abundance; for the years 2000-2010, the hatchery-origin component of female SRWC spawners was $\leq 20 \%$ (Winship et al., 2014). Ocean salmon fisheries are sampled by the CDFW with a goal of sampling at least $20 \%$ of the harvest in each month, management area, and fishery sector. Heads are taken from all fish with a clipped adipose fin for codedwire tag extraction and reading. A total of 4036 codedwire tag recoveries were used in cohort reconstructions, 554 of which were from ocean fisheries (commercial and recreational), whereas the vast majority of the remaining recoveries were from spawner escapement surveys. Recreational, river harvest of SRWC is rare because of closures to the Sacramento River salmon fishery during much of the migration and spawning period.

Contact rates and fishing effort estimated for each month, area, and sector open to fishing in 2000-2012 were used to calculate the contact rate per unit of effort. For hindcasting purposes, values of the contact rate per unit of effort were derived for the entire period of 1978 to 2012 with the application of the bootstrap method to the estimates of contact rates per unit of effort for 2000-2012 (Efron and Tibshirani, 1993). These derived values of contact rate per unit of effort were then multiplied by the corresponding observed fishing effort for 1978-2012 to yield a set of contact rate hindcasts (Eq. 3). The bootstrap method used to characterize the contact rates per unit of effort is described later in the "Bootstrap" subsection. For strata for which these rates could not be estimated from available data sources, 2 methods were used to infer contact rates per unit of effort.

Data sufficient for estimation of contact rates per unit of effort for recreational fisheries during February and March are not available because recreational

\footnotetext{
${ }^{7}$ PSC (Pacific Salmon Commission). 2005. Report of the expert panel on the future of the coded wire tag program for Pacific salmon. Pacific Salmon Comm. Tech. Rep. 18, 230 p. [Available at website.]
} 
fisheries in the 2000-2012 period were largely closed during these months. To infer contact rates per unit of effort for these strata, we used historical SRWC harvest data derived from marked (fin-clipped) natural-origin fish from the brood years 1969-1970 that were recovered in ocean fisheries as age-3 fish during the calendar years 1971-1972 (CDFG8). Recreational fisheries in SF and MO in 1971-1972 opened in midFebruary with a 22 -in $(56-\mathrm{cm})$ minimum size limit, and this timing of the start of the season and this minimum size restriction were similar for recreational fishing seasons through 1983. The average proportion of the recreational harvest of age-3 SRWC south of Point Arena that was taken in February-March for the years 1971-1972 $\left(\phi_{1}\right)$ was 0.33 . This proportion was assumed to be representative of the average fraction of the recreational harvest south of Point Arena that was taken in February and March for the years 1978-1983 $\left(\phi_{2}\right)$. Assuming that the contact rate per unit of effort was equivalent for February and March, and in management areas SF and MO, we used the root finding function uniroot in the $\mathrm{R}$ statistical software, vers. 3.0.0 ( $\mathrm{R}$ Core Team, 2013) to identify the value of contact rate per unit of effort that resulted in the difference between $\phi_{1}$ and $\phi_{2}$ that equaled zero. Put another way, we solved iteratively for the contact rates per unit of effort for February-March that resulted in 33\% of the total recreational sector harvest occurring in February-March, on average, for the years 1978-1983.

Data sufficient for estimation of contact rates per unit of effort also do not exist for the commercial sector in $\mathrm{SF}$ or $\mathrm{MO}$ in April and for the recreational sector in MO in October because fisheries in the 2000-2012 period were largely closed for these months. In the case when SF and MO commercial fisheries began in April, the estimate of contact rate per unit of effort for May was assumed. In the case when MO recreational fisheries extended into October, the contact rate per unit of effort for September was assumed. These assumptions had little effect on the results because April commercial fisheries and MO recreational fisheries in October were relatively rare, were short in duration, and attracted little effort.

The proportion of SRWC expected to be of legal size for retention was determined on the basis of a sizeat-age model derived for SRWC, described in O'Farrell et al. (2012a, 2012b), and the specified minimum size limit for retention in a fishery. For the growth model, the size-at-age of individual fish in each month is assumed to be normally distributed, and the proportion of legal-size fish is estimated by evaluating the cumulative normal distribution at the minimum size limit, given the estimated mean and standard deviation. When a large minimum size limit is in effect for months when SRWC size-at-age is smallest (i.e., February-May), very low estimates of the proportion of legal-

\footnotetext{
${ }^{8}$ CDFG (Calif. Dep. Fish Game). 1989. Unpubl. report. Description of the winter Chinook Ocean Harvest Model. Ocean Salmon Project, Calif. Dep. Fish Game, Santa Rosa, CA.
}

size fish can result. This scenario can translate into unrealistically low levels of harvest per contacted fish, and, conversely, into a very large estimate of contacts based on a single retained and sampled fish. As a result, a lower bound on the proportion of legal-size fish of 0.035 is assumed. The value of 0.035 corresponds to the condition where a single coded-wire tag recovery results in contacts approximately equivalent to the lowest reconstructed abundance of age-3 fish estimated from cohort reconstruction (O'Farrell et al., 2012a). Use of this lower bound value reduces the probability that an entire hatchery-origin cohort would be estimated to be contacted by the fishery in order to produce one harvested and sampled fish. Table 1 displays the sizeat-age model parameters and the proportion of legalsize fish estimated for commonly employed minimum size limits in both the commercial and recreational fisheries.

Release mortality rates were assumed to be 0.26 for the commercial sector and 0.14 for the recreational sector, reflecting the conventional values used for the annual assessment of SRWC and other Chinook salmon stocks $\left(\mathrm{PFMC}^{4}\right)$. An exception exists in the recreational sector, where release mortality rates for 1990-2012 were estimated on the basis of prevalence of mooching (drifting a hooked bait in the California recreational sector), and fish contacted with mooching gear experience a higher rate of gut hooking and, therefore, a higher release mortality rate than that of troll-contacted fish (Grover et al., 2002). Derived from the results in Grover et al. (2002), estimates of the recreational release mortality rate range from 0.14 to 0.57 between 1990 and 2012 (Grover ${ }^{9}$.

The dropoff mortality rate was assumed to be 0.05 for all months, areas, and sectors, reflecting the conventional value used for PFMC Chinook salmon assessment $\left(\mathrm{PFMC}^{4}\right)$.

The natural mortality rate was assumed to be 0.018 , the monthly rate corresponding to an annual natural mortality rate of 0.20 . The annual natural mortality rate of 0.20 is commonly assumed in many stock assessments (Quinn and Deriso, 1999) and is consistent with many PFMC Chinook salmon assessments (e.g., O'Farrell et al., 2012a, 2012b).

\section{Bootstrap}

A key source of uncertainty in the hindcasting of impact rates is variation in estimates of contact rates per unit of effort across years. To account for this variation, we performed 20,000 replicate computations of the impact rate for the years 1978-2012 by randomly sampling, with replacement, estimates of the contact rate per unit of effort from the years 2000-2012. This procedure effectively makes the assumption that annual variation in contact rate per unit of effort in 2000-2012 is representative of the entire time series for 1978-2012. For

\footnotetext{
${ }^{9}$ Grover, A. 2013. Personal commun. Institute of Marine Sciences, Univ. Calif., Santa Cruz, Santa Cruz, CA 95064.
} 


\section{Table 1}

Estimates of the mean $(\mu)$ and standard deviation $(\sigma)$ of the size-at-age distribution, by month, and the resulting proportion of legal-size fish $(p)$ under three commonly employed minimum size limits $(l)$. Size units are total length in inches.

\begin{tabular}{clccccc}
\hline & & & & \multicolumn{3}{c}{$p$} \\
\cline { 5 - 7 } Year & Month & $\mu$ & $\sigma$ & $l=20$ & $l=24$ & $l=26$ \\
\hline \multirow{2}{*}{$y$} & Feb & 19.74 & 1.66 & 0.438 & 0.035 & 0.035 \\
& Mar & 20.77 & 1.70 & 0.674 & 0.035 & 0.035 \\
& Apr & 21.85 & 1.79 & 0.849 & 0.115 & 0.035 \\
& May & 22.94 & 1.88 & 0.941 & 0.286 & 0.052 \\
& Jun & 24.02 & 1.97 & 0.979 & 0.504 & 0.157 \\
& Jul & 25.10 & 2.06 & 0.993 & 0.704 & 0.331 \\
& Aug & 26.20 & 2.15 & 0.998 & 0.847 & 0.537 \\
& Sep & 27.28 & 2.24 & 0.999 & 0.929 & 0.717 \\
& Oct & 28.37 & 2.33 & 1.000 & 0.970 & 0.846 \\
& Nov & 29.45 & 2.41 & 1.000 & 0.988 & 0.923 \\
& Dec & 29.72 & 2.44 & 1.000 & 0.991 & 0.937 \\
$y+1$ & Jan & 29.21 & 2.40 & 1.000 & 0.985 & 0.910 \\
& & & & & & \\
\hline
\end{tabular}

each replication, an estimate of contact rate per unit of effort was sampled independently for each month, management area, and sector in the period 2000-2012 and applied to the years 1978-2012. For the inferred contact rate per unit of effort in February and March for the recreational fishery, the root-finding procedure was performed as previously described in each of the 20,000 replications. Impact-rate uncertainty was characterized by the 0.68 percentile interval of the 20,000 replication bootstrap distribution (Efron and Tibshirani, 1993). For a normally distributed estimator, the 0.68 percentile interval corresponds to the mean \pm 1 standard error (Zar, 1999).

\section{Results}

Model results provide evidence that the highest impact rates occurred between the mid-1980s and the mid-1990s followed by a substantial decrease (Fig. 3). For several years in the period 1985-1995, the lower bound of the 0.68 percentile interval exceeded the upper bound of the 0.68 percentile interval for the post2000 period. The hindcasts from the impact-rate model generally captured the variation in the impact rates estimated directly from coded-wire tag data by using cohort reconstruction methods in recent years.

There was evidence for a substantial difference in the impact-rate trajectories between the commercial and recreational sectors (Fig. 4A). The impact-rate time series for the commercial sector showed a nearly monotonic decline from 1978 through 2012. In contrast, the impact rate for the recreational sector exhibited much more variation, and maximum impact rates occurred in the middle of the time series. This pattern of sectorspecific impact rates led to divergence in the proportions of the impact rate attributable to the 2 sectors over time (Fig. 4B). In the early portion of the time series (before the mid-1980s), the commercial and recreational sectors contributed approximately equally to the total impact rate. Subsequently, the share of the impact rate attributed to the recreational sector increased and stabilized at approximately $80 \%$ of the overall impact rate.

Estimates of contact rates per unit of effort that were used to inform the impact-rate hindcasts differed across fishery sectors and management areas (Fig. 5). Distributions of month-specific contact rates per unit of effort in most cases were skewed, with the mean exceeding the median. This pattern was most evident in the MO management area where the maximum contact rates per unit of effort in both the commercial and recreational sectors were much higher than the corresponding sectors in the SF manage-
Time series of hindcast impact rates for the years 1978-2012 for Sacramento River winter Chinook salmon (Oncorhynchus tshawytscha) south of Point Arena, California. The black line represents the median, and the shaded area indicates the 0.68 percentile interval of the bootstrap distribution. The dots indicate estimates of the impact rate derived with cohort reconstruction methods. 

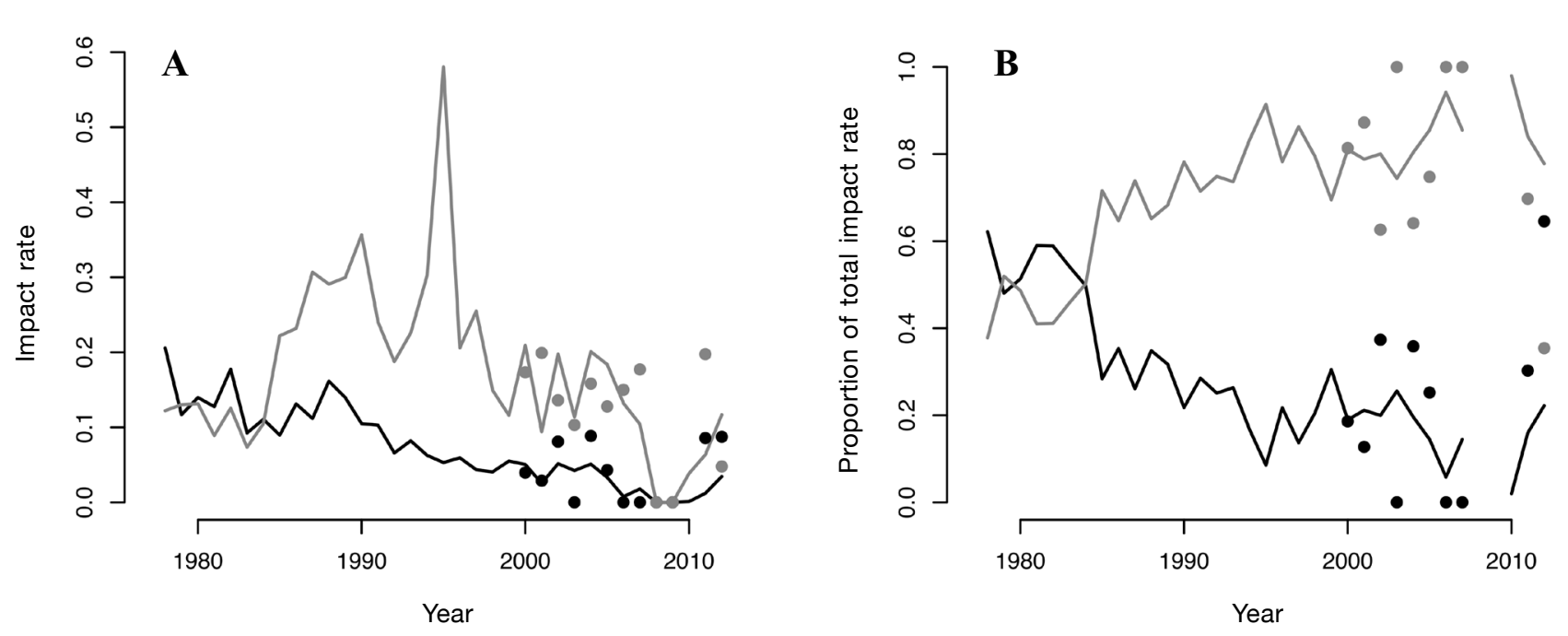

Figure 4

Estimates of the median (A) impact rates and (B) impact rate proportions for Sacramento River winter Chinook salmon (Oncorhynchus tshawytscha) south of Point Arena, California, for the commercial (black lines) and recreational (gray lines) sectors. The dots indicate estimates of the impact rates derived with cohort reconstruction methods.

ment area, and, therefore, there were larger differences between the median and mean estimates of the contact rate per unit of effort in $\mathrm{MO}$ in relation to $\mathrm{SF}$. In many cases, the median contact rates per unit of effort were zero, particularly in the commercial sector. For recreational fisheries in February and March, inferred contact rates per unit of effort were much higher than estimates for other months. These values were higher than all estimates of contact rates per unit of effort in the SF management area and were among the highest values observed in the MO area. These high contact rates per unit of effort were not unexpected given the high proportion of the total harvest that occurred in February and March, according to estimates derived from the data for 1971-1972 $\left(\phi_{1}=0.33\right)$, and given the low estimates of the proportion of legal-size fish for these months (Table 1). High levels of contact rates per unit of effort in February and March would be required to result in the substantial harvest proportions in those months and, therefore, to approximate the monthly harvest distributions from the data for 1971-1972.

To evaluate whether the impact-rate hindcasts had a pattern similar to measures of fishing mortality for other stocks subjected to a common ocean fishery, we compared the median SRWC impact-rate hindcasts with Sacramento River fall Chinook salmon (SRFC) harvest rates directly estimated from coded-wire tag data. The SRFC stock is the largest contributor to ocean salmon fisheries south of Point Arena. Harvest rates were estimated by computing the ratio of SRFC adult (ages 3-5) harvest south of Point Arena to the Sacramento Index (the Sacramento Index is the sum of ocean harvest south of Cape Falcon, Oregon; river harvest; and spawner escapement; see O'Farrell et al., 2013, for a detailed description). The impact-rate hindcasts for SRWC were highly correlated to SRFC harvest rates in 1983-2012, the years for which the SRFC harvest rate is estimable (correlation coefficient $[r]=0.827, P<0.001$ ) (Fig. 6).

\section{Discussion}

The large changes in California ocean salmon fisheries over the past 35 years have resulted in substantial changes to the levels of fishing mortality experienced by SRWC. Impact-rate hindcasts indicate lower rates in the 2000s than those in the mid-1980s through the mid-1990s. A decline in the impact rate was evident for the recreational sector following a peak in the 1980 s and 1990 s, and a decline has been observed for the commercial sector throughout the entire period. The trajectories of the sector-specific impact rates (Fig. 5A) reflect the observed changes in fishing effort (Fig. 2). The strong correlation between harvest rates for SRFC in the region south of Point Arena and the impact-rate hindcasts for SRWC, where both populations have been subjected to the same fisheries, supports the hindcasting methods for calculating impact rates used in this study.

In their analysis of the brood years 1998-2007, O'Farrell et al. (2012a) reported that exploitation rates experienced by SRWC averaged approximately $20 \%$ and that the bulk of the ocean impacts were the result of the recreational sector. Although the results from our study are consistent with O'Farrell et al. (2012a) over the common time period, they indicate that recent estimates of the impact rate are unlikely to represent the 


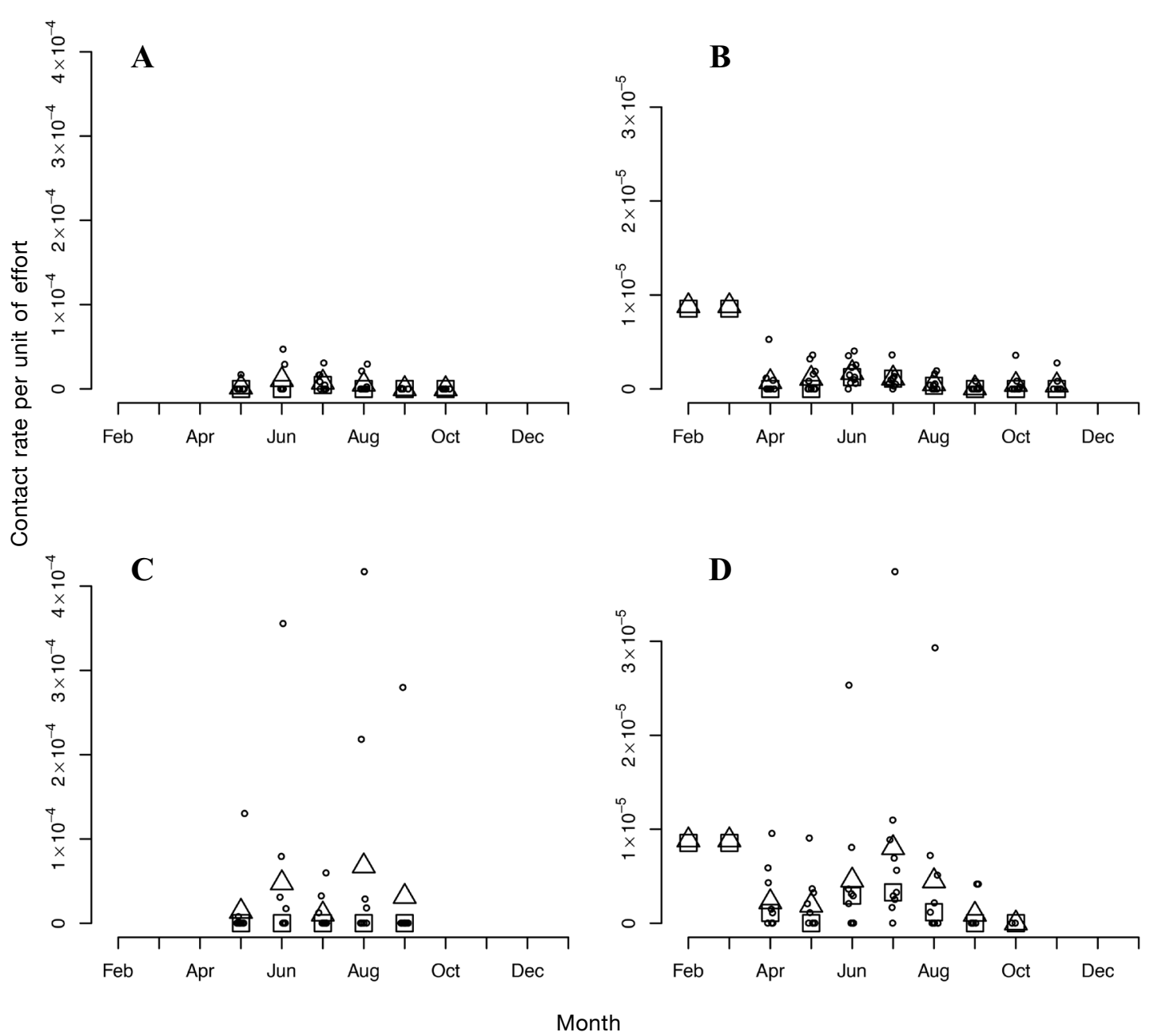

Figure 5

Sacramento River winter Chinook salmon (Oncorhynchus tshawytscha) contact rates per unit of effort for the (A) commercial and (B) recreational sectors in the San Francisco (SF) management area and for the (C) commercial and (D) recreational sectors in the Monterey (MO) management area. Circles denote estimated values for individual years, triangles indicate mean values, and squares denote median values. The methods used to infer mean and median contact rates per unit of effort for the recreational sector in February and March are described in the text.

degree of fishery exploitation experienced by SRWC in earlier years. These impact-rate hindcasts were used to extend the SRWC stock assessment and have contributed important fishing mortality inputs to a life-cycle model for this population (Hendrix et al., 2014). More generally, an extended time series of fishing mortality rates derived with the methods described here could allow for an extended reconstruction of recruit abundance useful for stock-recruit analysis ( $\left.\mathrm{PSC}^{10}\right)$.

10PSC (Pacific Salmon Commission). 1999. Maximum sustained yield or biologically based escapement goals for selected Chinook salmon stocks used by the Pacific Salmon Commission's Chinook Technical Committee for escapement assessment, vol. 1. Pacific Salmon Comm. Joint Chinook
The impact-rate estimates derived from cohort reconstruction for 2000-2012 reflect many layers of salmon fishery regulations. In particular, ocean fisheries in California frequently have been constrained by conservation concerns and ocean-versus-river fishery allocations for Klamath River fall Chinook salmon (Prager and Mohr, 2001). A collapse of the SRFC stock (Lindley et al., 2009) closed nearly all California ocean salmon fisheries in 2008 and 2009 and heavily constrained fisheries in 2010. The first SRWC-specific constraints to fisheries began after the species was list-

Tech. Comm. Rep. TCCHINOOK (99)-3, 104 p. [Available at website.] 
ed as threatened under the ESA in 1989. Fishing constraints included establishment of a closed area for the recreational sector near the mouth of San Francisco Bay and implementation of river fishery restrictions (PFMC11). Since those initial SRWC conservation measures were implemented, additional SRWC-focused fishery management measures have been established, including truncation of commercial and recreational fishing seasons, increased minimum size limits, and most recently, impact-rate "caps" set annually by a control rule (see Appendix C in $\mathrm{PFMC}^{12}$ ). Although we do not directly link changes in the impact rate to particular management measures, the increased fishery constraints over the past 35 years have clearly influenced the impact rate.

Estimates of contact rates per unit of effort have a strong effect on the impact-rate forecasts made with the Winter Run Harvest Model (O'Farrell et al., 2012b) and, therefore, on the hindcasts presented here. We assumed that contact rates per unit of effort estimated with cohort reconstruction methods for the years 2000-2012 are representative of contact rates per unit of effort in the years before 2000. Contact rates per unit of effort are a function of catchability and stock distribution, and, in the absence of large temporal changes in these components, assuming contemporary contact rates per unit of effort for past years without direct estimates is reasonable. Large changes in catchability in either the commercial or recreational salmon sectors would be unlikely because modes of fishing and associated fishing gear have changed little over the past 35 years. We would also not expect substantial shifts in SRWC ocean distribution over time because this population has been shown to have a relatively compact southerly distribution (O'Farrell et al., 2012a; Satterthwaite et al., 2013).

Nevertheless, there is likely to be nontrivial process and measurement error associated with the estimates of contact rates per unit of effort. Local conditions undoubtedly affect both the ability of fishing fleets to contact SRWC and the precise local concentration of SRWC cohorts. With regard to sampling error, estimates of contact rates per unit of effort are made by using expanded coded-wire tag data and estimates of fishing effort. SRWC coded-wire tag recoveries can be relatively rare for a variety of reasons. SRWC have a lower abundance than that of other Chinook stocks

\footnotetext{
${ }^{11}$ PFMC (Pacific Fishery Management Council). 1990. Preseason report III: analysis of Council-adopted management measures for 1990 ocean salmon fisheries. Pacific Fishery Management Council, 24 p. Portland, OR. [Available at website.]

12PFMC (Pacific Fishery Management Council). 2013. Preseason report I: tock abundance analysis and environmental assessment part 1 for 2013 ocean salmon fishery regulations, 135 p. (Document prepared for the Council and its advisory entities.) Pacific Fishery Management Council, Portland, OR. [Available at website.]
}

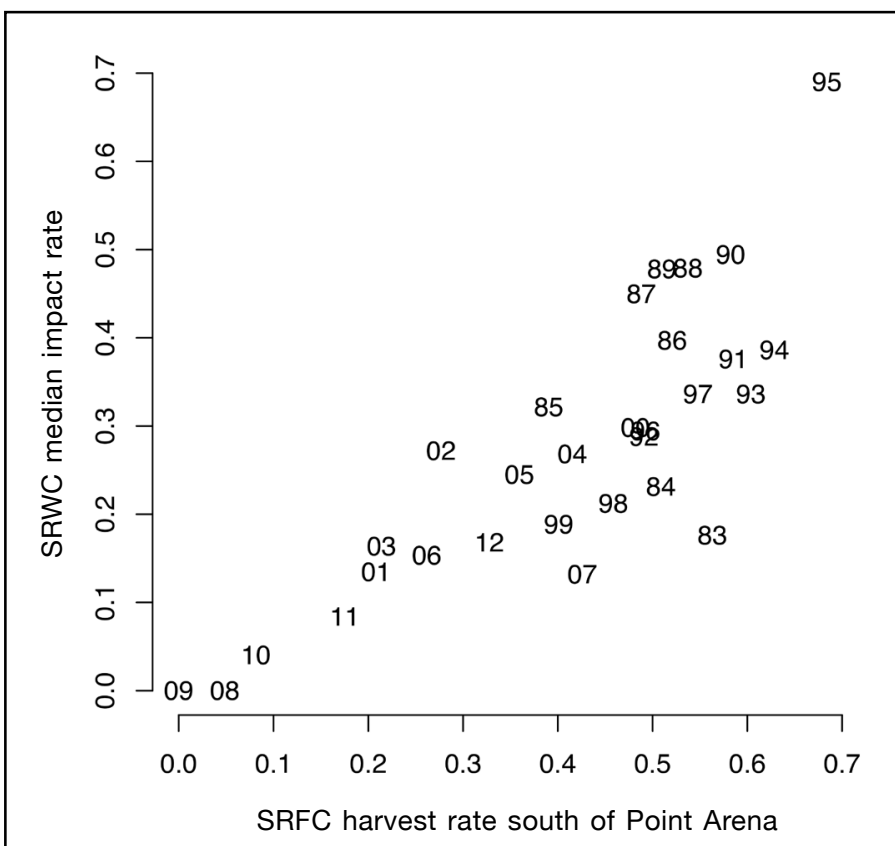

Figure 6

Sacramento River winter Chinook salmon (Oncorhynchus tshawytscha) (SRWC) hindcast median impact rates plotted as a function of Sacramento River fall Chinook salmon (SRFC) harvest rates for fisheries south of Point Arena, California. Numbers denote the calendar years 1983-2012.

that contribute to California fisheries, and only the hatchery-origin component of the population is marked and tagged. Approximately $20 \%$ of the landed catch is sampled, and early-season fisheries with large minimum size limits would be expected to retain few SRWC because few fish would be greater than the minimum legal size.

These sampling issues for rare stocks can readily lead not only to an estimate of zero contacts in a month, area, and sector stratum despite nonzero actual contacts but also to cases where a single tag recovery implies a very large number of contacts. In some strata, estimates of SRWC contact rates have been based on a very small number of coded-wire tag recoveries (O'Farrell et al., 2012a).

To infer values of potential contact rate per unit of effort for the recreational sector in February and March, we developed a method based on estimates of the monthly distribution of harvest when fisheries were open from February through November. The inferred recreational contact rates per unit of effort for February and March from this procedure were higher than estimates of contact rates per unit of effort from months after March, although such high values would be expected given the relatively large proportion of harvest that was estimated for 1971-1972 and the small proportion of age-3 SRWC expected to be greater than the minimum legal size limit during those months. 
However, these inferences may not adequately describe the pattern of SRWC contacts in these early months.

Given the data available, we were unable to make management-area-specific inferences of recreational contact rates per unit of effort for February and March; yet for later months, the estimated contact rates per unit of effort tended to be considerably higher in MO than in SF. Additionally, estimates of fishing effort for 1971-1972 do not exist; therefore, we assumed that the monthly distribution of effort in those years was similar to the distribution during the years 1978-1983. If substantial differences in effort occurred between these 2 periods, those differences would contribute to errors in the inferred recreational contact rates per unit of effort for February and March. Nonetheless, the monthly harvest estimates for 1971-1972 represent the only information on the temporal patterns of recreational harvest over the protracted seasons that characterized historical fishing.

To account for uncertainty in the hindcasts of impact rates, we incorporated the variation in estimates of contact rates per unit of effort using the bootstrap method. Although this approach did not account for the full spectrum of uncertainty (e.g., natural mortality rate and fishing effort), it is likely that variation in the estimated contact rates per unit of effort represents the dominant uncertainty because of the high level of variability across years and the strong effect that contact rates have on impact-rate projections. Characterizing uncertainty in contact rates per unit of effort by randomly resampling values for month, area, and sector strata, however, may have led to admitting excess uncertainty into the impact-rate hindcasts. For example, in years with extremely high fishing effort (e.g., 1995), a few replications produced unrealistic estimates where fishery impacts exceeded ocean abundance. This outcome was caused by randomly sampling a very high estimate of contact rate per unit of effort that was then multiplied by a very high, stratum-specific effort estimate. This outcome is clearly not tenable and correlations may exist between the contact rate per unit of effort and fishing effort that would prevent extinction by ocean fishing. However, strong evidence of correlations between contact rate per unit of effort and fishing effort were not observed (senior author, unpubl. data), and no covariance structure was incorporated into the simulation framework.

Ultimately, there is a need to understand the effects of all sources of mortality on the dynamics of the endangered SRWC population to better explain its population dynamics. Winship et al. (2014) estimated low overall productivity for SRWC, likely owing to low fecundity and low juvenile survival rates, which resulted in low sustainable fishing mortality rates. In the absence of hatchery supplementation, Winship et al. (2014) estimated a median maximum sustainable level of fishing mortality (analogous to maximum sustainable yield) at an impact rate of 0.17 , as well as a rate of 0.25 under recent levels of hatchery supplementation. Regular hatchery supplementation began in 1998 at the SRWC-dedicated Livingston Stone National Fish Hatchery, with little or no hatchery-origin contributions to the population in prior years.

Given the low sustainable impact rates estimated by Winship et al. (2014), and the relatively high median impact rates inferred for the 1980s and $1990 \mathrm{~s}$, it is likely that impact rates exceeded maximum sustainable fishing mortality levels and that they could have reached levels identified as unsustainable under conditions with no hatchery supplementation. However, we note that there was substantial uncertainty estimated for both the maximum sustainable impact rates in Winship et al. (2014) and the historical impact rates inferred here. In addition, the results of Winship et al. (2014) were derived with contemporary (post-1998) data, and it is not known whether the estimated productivity, and, therefore, sustainable impact rates, are applicable for earlier time periods.

Although we present a specific case study for SRWC, our ability to hindcast exploitation rates (for years before the existence of sufficient data that would have allowed direct estimation of exploitation rates) should be useful for other fishery applications. The use of forward projection models in a hindcasting mode can help with a better understanding of the relative effects of past fisheries and management actions on fish stocks. Approaches such as the one developed here have the potential to be useful for integrating long-term records with existing stock assessments and for performing retrospective evaluations of the effectiveness of management measures in data-limited situations.

\section{Acknowledgments}

We would like to thank A. Grover for sharing his insight into historical salmon fisheries and fishery sampling in California. We are also grateful for the thoughtful and thorough reviews provided by M. Mohr, N. Hendrix, and 3 anonymous reviewers.

\section{Literature cited}

Efron, B., and R. J. Tibshirani.

1993. An Introduction to the Bootstrap, 436 p. Chapman \& Hall, New York.

Federal Register.

1994. Endangered and threatened species; status of Sacramento River Winter-run Chinook salmon; final rule. Federal Register 59:440-450. [Available at website.]

Fisher, F. W.

1994. Past and present status of Central Valley Chinook salmon. Conserv, Biol. 8:870-873. Article

Grover, A. M., M. S. Mohr, and M. L. Palmer-Zwahlen.

2002. Hook-and-release mortality of Chinook salmon from drift mooching with circle hooks: management implications for California's ocean sport fishery. In Catch and release in marine recreational fisheries (J. A. Lucy and A. L. Studholme, eds.), p. 39-53. Am. Fish. Soc., Bethesda, MD. 
Haltuch, M. A., A. E. Punt, and M. W. Dorn.

2008. Evaluating alternative estimators of fishery management reference points. Fish. Res. 94:290-303. Article

Hendrix, N., A. Criss, E. Danner, C. M. Greene, H. Imaki, A. Pike, and S. T. Lindley.

2014. Life cycle modeling framework for Sacramento River winter-run Chinook salmon. NOAA Tech. Memo. NMFS-SWFSC-530, 26 p. [Available at website.]

Hilborn, R., and C. J. Walters.

1992. Quantitative fisheries stock assessment: choice, dynamics, and uncertainty, 570 p. Chapman \& Hall, New York.

Johnson, J. K.

1990. Regional overview of coded wire tagging of anadromous salmon and steelhead in northwest America. Am. Fish. Soc. Symp. 7:782-816.

Lapi, L., M. Hamer, and B. Johnson.

1990. Data organization and coding for a coastwide mark-recovery data system. Am. Fish. Soc. Symp. 7:720-724.

Lindley, S. T., C. B. Grimes, M. S. Mohr, W. Peterson, J. Stein, J. T. Anderson, L. W. Botsford, D. L. Bottom, C. A. Busack, T. K. Collier, J. Ferguson, J. C. Garza, A. M. Grover, D. G. Hankin, R. G. Kope, P. W. Lawson, A. Low, R. B. MacFarlane, K. Moore, M. Palmer-Zwahlen, F. B. Schwing, J. Smith, C. Tracy, R. Webb, B. K. Wells, and T. H. Williams.

2009. What caused the Sacramento River fall Chinook stock collapse? NOAA Tech. Memo. NMFS-SWFSC-447, 61 p. [Available at website.]

Milner, G. B., D. J. Teel, F. M. Utter, and G. A. Winans. 1985. A genetic method of stock identification in mixed populations of Pacific salmon, Oncorhynchus spp. Mar. Fish. Rev. 47(1):1-8.

Myers, J. M., R. G. Kope, G. J. Bryant, D. Teel, L. J. Lierheimer, T. C. Wainwright, W. S. Grant, W. F. Waknitz, K. Neely, S. T. Lindley, and R. S. Waples.

1998. Status review of Chinook salmon from Washington, Idaho, Oregon, and California. NOAA Tech. Memo. NMFS-NWFSC-35, 443 p. [Available at website.]

Nandor, G. F., J. R. Longwill, and D. L. Webb.

2010. Overview of the coded wire tag program in the greater Pacific region of North America. In PNAMP special publication: tagging, telemetry and marking measures for monitoring fish populations-a compendium of new and recent science for use in informing technique and decision modalities (K. Wolf and J. O’Neal, eds.), p. 5-46. Pacific Northwest Aquatic Monitoring Partnership Spec. Publ. 2010-002. [Available at website.]

O'Farrell, M. R., S. D. Allen, and M. S. Mohr.

2012b. The Winter-Run Harvest Model (WRHM). NOAA Tech. Memo. NMFS-SWFSC-489, 17 p. [Available at website.]
O'Farrell, M. R., M. S. Mohr, A. M. Grover, and W. H. Satterthwaite.

2012a. Sacramento River winter Chinook cohort reconstruction: analysis of ocean fishery impacts. NOAA Tech. Memo. NMFS-SWFSC-491, 68 p. [Available at website.]

O'Farrell, M. R., M. S. Mohr, M. L. Palmer-Zwahlen, and A. M. Grover.

2013. The Sacramento Index (SI). NOAA Tech. Memo. NMFS-SWFSC-512, 36 p. [Available at website.]

Prager, M. H., and M. S. Mohr.

2001. The harvest rate model for Klamath River fall Chinook salmon, with management applications and comments on model development and documentation. N. Am. J. Fish. Manage. 21:533-547. Article

Quinn, T. J., and R. B. Deriso.

1999. Quantitative fish dynamics, 560 p. Oxford Univ. Press, New York.

$\mathrm{R}$ Core Team.

2013. R: a language and environment for statistical computing. R Foundation for Statistical Computing, Vienna, Austria. [Available from website, accessed April 2013.]

Restrepo, V. R., and J. E. Powers.

1999. Precautionary control rules in US fisheries management: specification and performance. ICES J. Mar. Sci. 56:846-852. Article

Satterthwaite, W. H., M. S. Mohr, M. R. O'Farrell, E. C. Anderson, M. A. Banks, S. J. Bates, M. R. Bellinger, L. A. Borgerson, E. D. Crandall, J. C. Garza, B. J. Kormos, P. W. Lawson, and M. L. Palmer-Zwahlen.

2014. Use of genetic stock identification data for comparison of the ocean spatial distribution, size at age, and fishery exposure of an untagged stock and its indicator: California Coastal versus Klamath River Chinook Salmon. Trans. Am. Fish. Soc. 143:117-133. Article

Satterthwaite, W. H., M. S. Mohr, M. R. O'Farrell, and B. K. Wells.

2013. A comparison of temporal patterns in ocean spatial distribution of California's Central Valley Chinook salmon runs. Can. J. Fish. Aquat. Sci. 70:574-584. Article

Winship, A. J., M. R. O'Farrell, and M. S. Mohr.

2014. Fishery and hatchery effects on an endangered salmon population with low productivity. Trans. Am. Fish. Soc. 143:957-971. Article

Weitkamp, L. A., and K. Neely.

2002. Coho salmon (Oncorhynchus kisutch) ocean migration patterns: insight from marine coded-wire tag recoveries. Can. J. Fish. Aquat. Sci. 59:1100-1115. Article

Yoshiyama, R. M., F. W. Fisher, and P. B. Moyle.

1998. Historical abundance and decline of Chinook salmon in the Central Valley region of California. N. Am. J. Fish. Manage. 18:487-521. Article

Zar, J. H.

1999. Biostatistical analysis, $4^{\text {th }}$ ed., 663 p. PrenticeHall, NJ. 